\title{
Non-English Words and Phrases
}

$\begin{array}{ll}\begin{array}{l}\text { bohlabela } \\ \text { e a lekana }\end{array} & \text { those of the East (seSotho) } \\ \text { bangane } & \text { it is equal (seSotho) } \\ \text { geld } & \text { friends (xiTsonga) } \\ \text { go balabala } & \text { to emphasize (seSotho) } \\ \text { go bea } & \text { to lay down or save (seSotho) } \\ \text { go bêrêka } & \text { to work (seSotho) } \\ \text { go hlôkômêla lapa } & \text { to care for the household (seSotho) } \\ \text { go ja } & \text { to eat (seSotho) } \\ \text { go ja tšhêlêtê } & \text { to waste money (seSotho) } \\ \text { go tšintšala } & \text { to exchange } \\ \text { ilobolo/lobola } & \text { bridewealth (isiZulu) } \\ \text { induna } & \text { headman, farm foreman (isiZulu) } \\ \text { ka kgwêdi } & \text { on account, lit. by the month (seSotho) } \\ \text { kapolô } & \text { removing mourning clothes, lit. unveiling } \\ \text { leoto } & \text { wheel (seSotho) } \\ \text { mashonisa } & \text { informal moneylender, loan shark (isiZulu) } \\ \text { modulasetulô } & \text { chairperson, leader } \\ \text { mošatê } & \text { chief's place (seSotho) }\end{array}$


xviii Non-English Words and Phrases

\begin{tabular}{|c|c|}
\hline nama, e a fella & flesh, from the head to the legs (seSotho) \\
\hline patêla & to pay (seSotho, from the Afrikaans, betaal) \\
\hline samp & $\begin{array}{l}\text { dried corn kernels that have been stamped until bro- } \\
\text { ken (native American origin) }\end{array}$ \\
\hline sekôlôtô & $\begin{array}{l}\text { debt (seSotho), from the Afrikaans, skuld, to owe; to } \\
\text { have guilt. }\end{array}$ \\
\hline skuld & debt, guilt (Afrikaans) \\
\hline spaza & small informal retailer \\
\hline setokofela & stokvel, savings club (seSotho) \\
\hline stokvel & $\begin{array}{l}\text { savings club (township vernacular, from "stock } \\
\text { fair") }\end{array}$ \\
\hline thiakene machaka & build yourselves, relatives (xiTonga) \\
\hline thušanang & help each other \\
\hline toyi-toyi & a protest dance (township vernacular) \\
\hline tšhêlêtê & money (seSotho), from the Afrikaans, geld \\
\hline unamêla kamêla & ride the camel (seSotho) \\
\hline
\end{tabular}

